\title{
Las técnicas emergentes en comunicación comercial y sus efectos percibidos. Un análisis descriptivo.
}

\author{
Teresa Pintado Blanco ${ }^{1}$ \\ Universidad Complutense de Madrid \\ Joaquín SÁNCHEz HerRerA ${ }^{2}$ \\ Universidad Complutense de Madrid
}

Recibido: 02/04/2013

Aceptado: 31/05/2013

\begin{abstract}
Resumen
En este trabajo empírico se analizan las percepciones asociadas a los efectos que se pueden atribuir a un conjunto relevante de nuevas técnicas de comunicación, que están adquiriendo una importancia cada vez mayor dentro de las estrategias de todo tipo de organizaciones. Entre ellas se encuentran la comunicación $360^{\circ}$, la comunicación viral, la comunicación móvil, el "engagement marketing" o la comunicación experiencial, aunque el abanico de técnicas estudiadas es mucho mayor. Para poder determinar los efectos asociados al conjunto de técnicas descrito, se realizó una investigación cualitativa que ayudó a definir los ítems más relevantes, y después se realizó una encuesta estructurada a una muestra de 237 directivos y mandos intermedios de marketing y comunicación, de diferentes sectores de actividad. Según los análisis efectuados, se pone de manifiesto que existen tres ejes claros de clasificación. En primer lugar, aparece un primer criterio de diferenciación, basado en la orientación estratégica o táctica en la comunicación. En segundo lugar, también se evidencia una diferenciación evidente entre técnicas con una orientación puramente dirigidas al recuerdo o notoriedad, frente a aquellas cuyos efectos atribuidos tienen más relación con la potenciación de relaciones y la modificación de comportamientos. En tercer lugar, aparece una diferenciación interesante entre las técnicas más orientadas a la producir efectos relacionados con la persuasión, frente a otras que pueden producir confusión en el receptor y que, en principio, deberían ser evitadas.

Palabras clave: efectos de la comunicación; técnicas de comunicación; tendencias en comunicación.
\end{abstract}

\section{Perceived effects of emerging communication tools. A descriptive approach.}

\begin{abstract}
In this empirical research, perceived effects of a relevant group of new communication tools, with an increasing importance across all kind of organizations, are analyzed. Communication 360, viral communication, mobile communication, engagement marketing or experiential communication are among them, although a broader range of communication techniques have been included in this work. In order to identify the most relevant characteristics of communications effects, a qualitative stage was developed. In a second stage, a structured questionnaire was applied to 237 marketing and communication managers from a variety of industries. According to our empirical findings, there are three different dimensions. First, one of the main classification criteria is strategic oriented versus tactical oriented communication. Secondly, it appears an interesting dichotomy between awareness-oriented communication tools versus those ones

${ }^{1}$ Departamento de Comercialización e Investigación de Mercados. Facultad de CC. Económicas y Empresariales. E-mail: teresa.pintado@ccinf.ucm.es.

${ }^{2}$ Departamento de Comercialización e Investigación de Mercados. Facultad de CC. de la Información. E-mail: joaquin.sanchez@ccee.ucm.es.
\end{abstract}


focused on creating relations and behavior modification. The third dimension shows a subset of communication tools related to persuasion effects, versus other tools that could cause disorientation and confusion in the target audience.

Key Words: communication effects; communication tools; communication trends.

\section{Introducción}

Uno de los problemas que actualmente más interés despiertan en el ámbito de la comunicación comercial, es la enorme cantidad de alternativas disponibles para emitir un mensaje, y los distintos modos en que esto puede hacerse. Además, en ello se invierten grandes presupuestos con el fin de llegar de forma adecuada a los públicos objetivos de las organizaciones. Según Infoadex, solamente en el año 2011, en España se alcanzó una inversión total en comunicación de 12.061 millones de euros, de los que más de la mitad $(54,4 \%)$, corresponden a inversiones en medios no convencionales (comunicación en el punto de venta, patrocinio, marketing móvil, etc.).

Entre estas técnicas no convencionales, han proliferado muchas que, o bien, son radicalmente novedosas, o bien, son una evolución importante de otras ya existentes, hasta el punto de percibirse como diferentes. La mayoría de estas técnicas están interconectadas e incluso se solapan unas con otras, de tal forma que en muchos casos, existen diferentes términos para denominar a técnicas distintas, o incluso, son conocidas con otras denominaciones según el país en que se estén aplicando. Concretamente, este trabajo se centra en el estudio de dieciséis técnicas emergentes: la comunicación $360^{\circ}$, la comunicación viral, el buzz marketing, la comunicación móvil, el advertainment, el engagement marketing, advergaming, street marketing, ambient marketing, la comunicación experiencial, la comunicación sensorial, el tryvertising, el micro-blogging, la comunicación a través de Redes Sociales, el marketing radical y el marketing de proximidad.

Dada la novedad de la mayor parte de estas herramientas de comunicación, aún estamos lejos de entender sus características básicas. Por ello, es interesante conocer qué es lo que perciben aquellos que son usuarios profesionales de estas técnicas, y también qué características deberían tener estos nuevos métodos (Sánchez y Pintado, 2010). De igual modo, además de esas características asociadas que ayudan a entender y a clasificar estas técnicas emergentes, es interesante conocer los efectos que se espera que produzcan en el destinatario del mensaje. En este sentido, nuestro trabajo trata de conocer qué es lo que se espera de estas nuevas técnicas, en términos de efectos conseguidos. Para ello, se ha utilizado una amplia muestra de profesionales del área de marketing y comunicación, con el fin de descubrir esos efectos asociados, y que se entenderán como las percepciones que dichos profesionales tienen de los efectos que las técnicas emergentes en comunicación producen en el consumidor.

En la revisión teórica realizada sobre estas técnicas emergentes, se ha podido observar que en algunas existen investigaciones académicas (como el caso de la comunicación viral, o WOM o "buzz marketing", y también en la comunicación móvil o a través de redes sociales), pero sin embargo, en otros casos, aunque los términos son conocidos, no existen demasiados estudios (la comunicación experiencial o el "ambient marketing", por ejemplo). Teniendo en cuenta estas diferencias en los conocimientos de las técnicas, se comprende que no haya, además, demasiados estudios comparativos que 
contemplen muchas de ellas a la vez: o bien, se realizan análisis individuales, o bien, se plantean comparaciones pareadas entre distintas técnicas emergentes de comunicación.

La comprensión sobre los efectos que los profesionales de la comunicación y del marketing atribuyen a estas técnicas emergentes, permitiría no sólo tener una base para poder elegir aquella que se adapte mejor a los objetivos planteados, sino a entender su complementariedad y las posibles sinergias que se pudieran generar al aplicarlas.

\section{Revisión Teórica}

Aunque no se hayan localizado estudios generales comparativos sobre el conjunto de técnicas de comunicación que se proponen en esta investigación, sí existen estudios académicos de buena parte de ellas. Estas investigaciones pueden diferir en su planteamiento y metodología, pero comparten un interés creciente sobre el análisis de sus características, idoneidad y eficacia en el marco de las decisiones de comunicación y marketing. Desde el punto de vista de la revisión teórica necesaria para nuestro trabajo, se ha optado por destacar los estudios e investigaciones académicas más relevantes en la literatura, subrayando aquellos casos en los que el objeto principal de estudio son los efectos de una técnica o las comparaciones con otras técnicas semejantes.

Entre las técnicas que se abordan en este estudio, una de las que están despertando el interés de la comunidad científica es la comunicación $360^{\circ}$, que utiliza de forma combinada todos los instrumentos y técnicas de comunicación con el fin de llegar al público objetivo previamente definido; entre todos los medios debe haber un efecto sinérgico, que además, debe potenciar el diálogo y la interactividad con el consumidor. No existen estudios específicos sobre este término, aunque sí otros relacionados con conceptos diferentes, que tienen objetivos similares, ya que como se explicaba anteriormente, en muchos casos se utilizan términos distintos para técnicas de comunicación muy parecidas. En este sentido, uno de los conceptos más utilizados es el de "comunicaciones integradas de marketing" (integrated marketing communications) o IMC, en que ya en los años noventa (McArthur y Griffin, 1997) se analizó la importancia que la combinación de técnicas tenía en la planificación de una campaña, así como el responsable más adecuado que debía poner en marcha las estrategias de estas comunicaciones de marketing, y también las actividades y funciones de las técnicas propiamente dichas.

Además de la comunicación $360^{\circ}$, otro concepto que también ha tenido en cuenta los efectos sinérgicos de la combinación de diferentes campañas en distintos medios es el de "cross-media", que incluye medios visuales, escritos o Internet, verificando que de esta forma se alcanza una mejor exposición y comprensión del mensaje, potenciándose, por tanto, la efectividad de la campaña (Havlena, Cardarelli y De Montigny, 2007).

En algunos casos, se han desarrollado investigaciones en que se analizan los efectos "cross-media" entre diferentes tipos de campaña. De esta forma, Wang estudió los resultados de la integración entre una campaña realizada con mensajes a móviles SMS combinada con una campaña publicitaria en Internet; los resultados revelaron que de esta forma se potenciaban (a) la comprensión del mensaje, (b) las actitudes hacia la marca y (c) el refuerzo de la combinación de los medios (Wang, 2007).

La comunicación viral es ampliamente conocida, refiriéndose a la propagación rápida e incontrolada de las comunicaciones, es decir, como un virus. No obstante, en los 
estudios analizados es mucho más habitual hacer referencia al WOM (word of mouth) y al "buzz marketing" (Thomas, 2004; Smith, Coyle, Lightfoot y Scott, 2007); de nuevo, diferentes conceptos hacen referencia a técnicas de comunicación muy similares. Las investigaciones se centran, sobre todo, en el WOM, como comunicaciones informales entre consumidores sobre un producto o servicio (Miller y Lamas, 2010; Hansen, Arvidsson, Nielsen, Colleoni y Etter, 2011; Shukla, 2010; Chu, 2011). Existe un amplio número de estudios sobre esta herramienta: de esta forma, Christiansen y Tax llegaron a la conclusión de que el emisor y el receptor evaluaban las comunicaciones de diferente forma, incluso cuando acababan de ser recibidas, y además, la evaluación del receptor iba modificándose a medida que avanzaba el tiempo, por lo que podía haber variaciones entre el momento inmediatamente posterior a la recepción y un tiempo después (Christiansen y Tax, 2000).

También son estudiados el N-WOM (negative word of mouth), esto es, rumores negativos, y el P-WOM (positive word of mouth) en que se revelan las emociones experimentadas por el individuo (Wetzer, Zeelenberg y Pieters, 2007). Además, el eWOM (electronic WOM), cada vez adquiere mayor relevancia y tiene más influencia en las comunidades virtuales (Hung y Yiyan Li, 2007) y en los juicios y decisiones de los consumidores sobre los productos (Lee y Youn, 2009). Parte de los estudios realizados se han centrado en comparar los efectos del WOM en las redes sociales de Internet con respecto a las formas tradicionales de comunicación (Trusov, Bucklin y Pauwels, 2009), así como en contrastar los efectos del eWOM entre los teléfonos móviles y los ordenadores (Okazaki, 2009).

El "buzz marketing" también ha sido ampliamente estudiado desde hace años, y de la misma manera, sus efectos son virales, ya que se refiere a cómo una comunicación se amplifica al ser utilizada por una persona que ejerce una influencia activa o pasiva sobre otra; es un término, por tanto, asociado a los rumores, y se ha llegado a explicar cuáles son los factores determinantes en la construcción del "buzz" (Thomas, 2004; Kraus, Harms y Fink, 2010). Los estudios entre el público adolescente se han centrado, sobre todo, en analizar la importancia que para ellos tiene este tipo de comunicación, ya que son grandes usuarios de la misma. De esta forma, se ha llegado a la conclusión de que les gusta ser agentes del "buzz", e incluso se lo toman como un trabajo, en que no se plantean los problemas éticos que podrían aparecer al no revelar sus datos (Ahuja, Michels, Walker y Weissbuch, 2007). En cualquier caso, aunque la comunicación viral ha sido conocida durante muchos años, es en la actualidad cuando se ha valorado la importancia que tiene en las conversaciones del día a día, que muchas veces no se centran en marcas o productos específicos; por tanto, las empresas se sienten obligadas a estimular el "buzz" como forma contagiosa y espontánea de hablar de sus productos o servicios (Carl, 2006).

Como su nombre indica, la comunicación móvil utiliza como herramienta básica el teléfono móvil, y existen estudios muy variados al respecto. Ferris analizó las propiedades de utilizar el móvil como herramienta de comunicación, revelando que permitía (Ferris, 2007): (a) potenciar la interactividad, (b) utilizar bases de datos de potenciales clientes, (c) comprender mejor a los consumidores utilizando el data mining (minería de datos), (d) dirigir campañas concretas a targets muy específicos de clientes, (e) 
medir la eficacia de dichas campañas y (f) estudiar sus posibilidades como medio de pago. Varnali y Toker (2010) realizan una excelente revisión sobre las investigaciones realizadas hasta la fecha en este ámbito, y cada vez aparecen más estudios que atienden a categorías de productos concretas (Shankar, Venkatesh, Hofacker, y Naik, 2010), o a las diferencias interculturales (Gao, Sultan, y Rohm, 2010).

Por otra parte, Woo Jun y Lee analizaron la actitud del consumidor hacia la publicidad en el teléfono móvil, relacionando el uso del teléfono y la satisfacción, así como las actitudes hacia la publicidad y las intenciones de compra; con los resultados llegaron a elaborar un modelo publicitario móvil (Woo Jun y Lee, 2007). Otro estudio de estas características, se centra en los factores que influyen en el consumidor cuando utiliza los servicios móviles (publicidad, servicios de información, además de la proyección futura del m-commerce), verificándose que el móvil puede cumplir una función socioemocional que permite demostrar cercanía, solidaridad o simpatía en las llamadas frecuentes a amigos (Mort y Drennan, 2007). Asimismo, hay análisis específicos sobre la aceptación de la publicidad permitida a través del Bluetooth entre los jóvenes (Leek y Christodoulides, 2009), así como de la recibida a través de $\mathrm{SMS}^{3}$ (Bamba y Barnes, 2007).

Aunque no es tan habitual, también existen referencias sobre el marketing de proximidad, que se utiliza para enviar comunicaciones inalámbricas al teléfono móvil de una persona cuando está pasando por una determinada zona (utilizando tecnología Bluetooth). En este sentido, Haines realizó un estudio con el fin de analizar las ventajas e inconvenientes del marketing de proximidad aplicado al "sponsorship", y cómo podía incrementar el valor de la marca y rentabilizar las inversiones en comunicación (Haines, 2009; Romanov, 2012).

Por otra parte, la comunicación a través de las redes sociales ("social-networking") también es ampliamente estudiada, ya que impacta en todo tipo de públicos. Existen estudios sobre diferentes herramientas relacionadas con las redes sociales (Cole, 2007): blogs en que los individuos incluyen sus experiencias y opiniones periódicamente, chats con conversaciones a tiempo real, micro-blogging que permite a los usuarios publicar mensajes breves de texto con un envío inmediato a las personas suscritas, así como las redes sociales propiamente dichas, como un espacio en la web en que se potencian los grupos de amigos y conocidos a través de invitaciones (Noort, Antheunis, y Reijmersdal, 2012).

El consumidor de redes sociales también se ha analizado desde diferentes puntos de vista. En este sentido, Cole ha estudiado el comportamiento en la búsqueda de información, en el que existen múltiples facetas, como se puede observar en la Tabla 1 (Cole, 2007).

Tabla 1. Búsqueda de información en el consumidor de redes sociales (Cole, 2007)

${ }^{3}$ Short message service, mensajes cortos de texto. 


\begin{tabular}{|c|c|c|}
\hline Redes Sociales & Búsqueda de información & Función social \\
\hline E-mail & 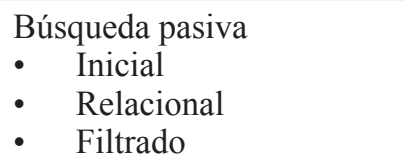 & $\begin{array}{l}\text { Comunicación } \\
\text { Socialización }\end{array}$ \\
\hline Marcadores Sociales & $\begin{array}{l}\text { Búsqueda activa } \\
\text { - } \quad \text { Diferenciación } \\
\text { - } \quad \text { Extracción }\end{array}$ & $\begin{array}{l}\text { Colaboración } \\
\text { Descubrimiento de recursos }\end{array}$ \\
\hline Foros de discusión & $\begin{array}{ll}\text { Búsqueda pasiva } \\
\text { - } & \text { Inicial } \\
\text { - } & \text { Relacional } \\
\text { - } & \text { Verificación }\end{array}$ & $\begin{array}{l}\text { Comunidad } \\
\text { Colaboración } \\
\text { Descubrimiento de recursos }\end{array}$ \\
\hline Blogs & $\begin{array}{l}\text { Búsqueda continua } \\
\text { - } \quad \text { Navegación } \\
\text { - } \quad \text { Control } \\
\text { - } \quad \text { Filtrado }\end{array}$ & $\begin{array}{l}\text { Comunidad } \\
\text { Colaboración }\end{array}$ \\
\hline Páginas de redes sociales & $\begin{array}{ll}\text { Atención pasiva } \\
\text { - } & \text { Inicial } \\
\text { - } & \text { Navegación } \\
\text { - } & \text { Diferenciación } \\
\text { - } & \text { Verificación }\end{array}$ & $\begin{array}{l}\text { Socialización } \\
\text { Comunicación }\end{array}$ \\
\hline
\end{tabular}

Además, se ha analizado la relación entre el consumidor de redes sociales y la efectividad del WOM, obteniéndose que gran parte del público está conectado, aunque sea de forma moderada, a una red social, y que aunque no sea un gran usuario de ella, siempre le gusta compartir datos y mensajes con otras personas, valorando el intercambio de información útil, además de evocarles sentimientos y emociones (Smith et. al, 2007). Asimismo, existen estudios centrados en las redes sociales desarrolladas con la utilización de los teléfonos móviles, en que se ha llegado a la conclusión de que los usuarios prefieren los mensajes publicitarios que reciben a través de otras personas conocidas en vez de los recibidos directamente por una empresa (Wais y Clemons, 2008).

Otra de las técnicas emergentes en comunicación es el "advertainment", combinación de "advertising" (publicidad) y "entertainment" (entretenimiento), que como su nombre indica, pretende aunar a ambos, incluyendo una marca o un producto dentro de los contenidos de una acción o programa de ocio (una película, programa de televisión, música, etc.). En Europa este concepto es conocido como "branded content", mientras que en Estados Unidos lo es como "branded entertainment" (Hudson y Hudson, 2006; Asquith, y Hearn, 2012), por lo tanto, de nuevo, una misma técnica está asociada a términos diferentes. Además, en ocasiones se ha considerado una evolución del "product placement" tradicional, pero en un contexto de entretenimiento que provoca una conexión emocional con el consumidor (Hudson y Hudson, 2006), por lo que la técnica de comunicación no sería novedosa en sí misma, pero sí lo sería esa perspectiva emocional. Existen diferentes estudios sobre esta técnica; de esta forma, Nelson, Keum y Yaros (2004) analizaron la actitud de los jugadores hacia la publicidad y el "product 
placement" en los juegos de ordenador, y los resultados indicaron que su actitud era positiva y no les importaba que las marcas apareciesen en los juegos cuando éstas añadían realismo, pero sin embargo, no había acuerdo sobre la influencia que dichas marcas podían tener, ya que algunos jugadores se sentían influidos y otros no. El "advergaming"4 también se relaciona con el "advertainment", aunque no se han encontrado estudios relevantes sobre esta técnica en particular.

El "engagement marketing", por otra parte, es una nueva técnica ligada a otros tipos de comunicación, que puedan potenciar la relación con el consumidor y la implicación que tiene con la marca, con el fin de que ésta sirva como entretenimiento; en este sentido, se ha estudiado cómo la comunicación de la marca basada en la puesta en marcha de experiencias y sensaciones (aspectos emocionales, por tanto) da lugar a este concepto de "engagement" en que el consumidor participa y tiene experiencias de primera mano con la marca, que favorecen su posterior aceptación y consumo (Whelan y Wohlfeil, 2006; Cambra, Melero, y Sese, 2012; Nammir, Marane, y Ali, 2012; Sashi, 2012). También es conocido el concepto de "advertising engagement", como una forma de comunicación que potencia el mensaje participativo, más creíble y con una efectividad mayor (Wang, 2006).

La comunicación experiencial se basa en los planteamientos realizados por Schmitt. Schmitt fue uno de los pioneros en analizar el marketing experiencial, diferenciando entre la percepción que el marketing tradicional tiene sobre el consumidor, según la cual, éste toma decisiones racionales de compra, y aquella del marketing experiencial, que percibe al consumidor como un ser humano tanto racional como emocional, que persigue experiencias placenteras (Lee, y Chang, 2012). De este modo, habría que tener en cuenta cinco tipos distintos de experiencias, relacionadas con (a) los sentidos, (b) los sentimientos, (c) los pensamientos, (d) los actos y (e) los relatos. Los proveedores de estas experiencias pasan a ser, por tanto, la comunicación, la identidad visual y verbal, la presencia del producto, los medios electrónicos, etc., de tal forma que esas experiencias individuales llegan a crear una experiencia integral u holística (Schmitt, 1999). En los últimos años, se han realizado estudios aplicados del marketing y la comunicación experiencial. Así, Petkus analizó la utilización del marketing experiencial en las artes (Petkus, 2004), y Jackson lo aplicó al "sponsorhip" (Jackson, 2009). La técnica del "tryvertising", aunque poco analizada, también está asociada a la comunicación experiencial, ya que se basa en hacer que los clientes prueben los productos integrados en una experiencia de uso real que sea significativa para ellos, por tanto, se busca la experimentación y familiarización con dicho producto.

La comunicación sensorial ("sensory communication" y "sensory marketing" en Estados Unidos) está muy ligada a la experiencial, aunque en la sensorial se utilizan los sentidos (vista, oído, tacto, gusto, olfato) de forma específica con el fin de impactar en los consumidores. Los estudios más habituales sobre comunicación sensorial son los relacionados con la utilización de los aromas en los establecimientos comerciales para estimular respuestas tanto emocionales como comportamentales (Davies, Kooijman y Ward, 2003; Bosmans, 2006), así como la asociación de los olores con marcas especí-

\footnotetext{
${ }^{4}$ Advertising y game: juegos a medida creados por las marcas, con el fin de interactuar con el jugador.
} 
ficas (Morrin y Ratneshwar, 2003). Además, existen algunos estudios sobre la influencia de la música en la percepción del entorno de los clientes (Morin, Dubé y Chebat, 2007), o la experiencia de tocar o entrar en contacto físico con el producto (Hultén, 2012). Aunque los estudios son menores, la comunicación sensorial también está unida con la "emotional communication" y el "emotional marketing", más centrados en las emociones que provocan esos sentidos.

Otra de las técnicas emergentes en comunicación es el "ambient marketing" ("ambient media" en Estados Unidos). Existen pocos estudios sobre este instrumento; uno de ellos es el realizado por Turk, Newton and Ewing para demostrar que la utilización de elementos de la vida cotidiana como herramienta de comunicación puede afectar al comportamiento de los individuos; en este caso, utilizaron los baños de bares y cafeterías de Indonesia para comunicar la importancia de la prevención del HIV/AIDS, demostrando que la efectividad de la campaña era mayor (Turk, Newton y Ewing, 2006). En el esfuerzo ya comentado de intentar definir y delimitar estas técnicas, destacan los estudios recientes de Jurca (2012) y de Belic y Jönsson (2012), quienes relaciones el ambient marketing y el marketing de guerrilla.

Finalmente, el "street marketing" es una herramienta que hace referencia a las acciones creativas que se desarrollan en espacios urbanos, aunque no hay estudios específicos sobre el tema. No obstante, es una evolución del denominado "guerrilla marketing" y el más reciente "radical marketing", que tampoco han sido objeto de estudios relevantes desde la perspectiva académica.

\section{Estudio empírico}

\subsection{Metodología}

Para investigar las percepciones asociadas a los efectos de cada técnica de comunicación, se realizaron cuatro reuniones de grupo, todas ellas formadas por directivos y mandos intermedios de marketing y comunicación, que fueron decisivas para poder seleccionar los atributos perceptuales relevantes. El criterio para la determinación del número de reuniones se basó en el principio de información redundante. El proceso es muy similar al proceso de comparación constante que se sigue en la Teoría Fundamentada (Glaser \& Strauss, 1967; Strauss \& Corbin, 1998).

Tras estas reuniones, el método de recogida de información elegido fue la encuesta online instrumentada a través de un cuestionario desarrollado a tal efecto. Se realizó un pretest de dicho cuestionario con 22 individuos, lo que permitió mejorar algunos de los ítems planteados y llegar al cuestionario definitivo.

Tabla 2. Relación de atributos analizados 


\section{ATRIBUTO}

Provoca sorpresa

Técnica muy efectiva

Facilidad en la medición de los resultados

La comunicación se propaga rápidamente

No es rentable

Mucha notoriedad

Muy persuasiva

Poco creíble

Difícil de comprender

Poca permanencia del mensaje

Ofrece una imagen positiva de la marca

Puede generar otras noticias o comentarios en los medios

Es útil para posicionar el producto

Se asocia a un precio o calidad altos

Sirve para modificar percepciones

Sirve para modificar comportamientos

Puede cambiar la actitud hacia un producto

Puede no ser entendida por el receptor

Puede molestar al receptor

Puede confundir al receptor

Potencia la relación con el receptor

\section{ABREVIATURAS}

SORPRESA

EFECTIVA

MEDICION

PROPAGA

NORENTA

NOTORIED

PRESUASI

NOCREIB

DIFICOMPR

NOPERMAN

IMAGEN

GENENOTI

POSICIO

CALIDAD

PERCEPCIO

COMPORTA

ACTITUD

NOENTEND

MOLESTA

CONFUND

RELACION

Las técnicas de comunicación seleccionadas para el estudio y los atributos finales que se incluyeron en el cuestionario, aparecen en las Tablas 2 y 3. Además, se adjuntan las abreviaturas que luego se utilizarán en la presentación de los resultados estadísticos y en las representaciones gráficas correspondientes.

Para el estudio de las relaciones entre los atributos y las técnicas mencionadas, se utilizó un Análisis Factorial de Correspondencias (AFC). Este tipo de análisis extrae relaciones entre un conjunto de categorías, a partir de una tabla de contingencia con datos de frecuencia. El avance definitivo en su desarrollo se le atribuye a Benzécri (1973), y su utilización en comunicación ha sido muy común en el estudio del posicionamiento de marcas. En esencia, el problema de representación consiste en encontrar los ejes principales que contienen la mayor proporción de inercia explicada. En términos formales, consiste en diagonalizar una matriz de frecuencias relativas $\mathrm{F}$ de dimensión $\mathrm{n} \mathrm{x}$ $\mathrm{p}$, de modo que:

$$
\mathbf{S}=\mathbf{F}^{\mathrm{T}} \mathbf{D}_{\mathrm{n}}^{-1} \mathbf{F} \mathbf{D}_{\mathrm{p}}^{-1} \quad \text { donde } \mathbf{D}_{\mathrm{p}} \text { es la matriz diagonal de la distrución marginal de }
$$

las filas y $\mathbf{D}_{\mathrm{p}}$ la de las columnas.

\subsection{Población y tamaño muestral}


La población objeto de análisis estaba integrada por directivos de comunicación y marketing, de varios de los sectores más representativos en términos de inversión en comunicación. Se emitieron 582 cuestionarios online que, tras descontar la ausencia de respuesta y los que se consideraron no válidos, quedaron 237 cuestionarios útiles.

Tabla 3. Técnicas de comunicación analizadas

$\begin{array}{ll}\text { ATRIBUTO } & \text { ABREVIATURA } \\ \text { Comunicación } 360^{\circ} & \text { COMTRES } \\ \text { Comunicación viral } & \text { COMVIR } \\ \text { Buzz marketing } & \text { BUZZ } \\ \text { Comunicación móvil } & \text { MOVIL } \\ \text { Advertainment } & \text { ADVERT } \\ \text { Engagement marketing } & \text { ENGAGE } \\ \text { Advergaming } & \text { ADVERG } \\ \text { Street marketing } & \text { STREET } \\ \text { Ambient marketing } & \text { AMBIENT } \\ \text { Comunicación experiencial } & \text { EXPERI } \\ \text { Comunicación sensorial } & \text { SENSOR } \\ \text { Tryvertising } & \text { TRYVE } \\ \text { Micro-blogging } & \text { MICRO } \\ \text { Comunicación a través de Redes Sociales } & \text { REDES } \\ \text { Marketing radical } & \text { RADICAL } \\ \text { Marketing de proximidad } & \text { PROXIMI }\end{array}$


Tabla 4. Reparto de la muestra por sectores de actividad

\begin{tabular}{lcc} 
SECTOR DE ACTIVIDAD & MUESTRA VÁLIDA (N) & PORCENTAJE \\
\hline Automoción & 21 & 8.86 \\
Alimentación y Bebidas & 37 & 15.61 \\
Banca y Actividades Financieras & 17 & 7.17 \\
Energía y Telecomunicaciones & 9 & 3.80 \\
Construcción y Obras Públicas & 12 & 5.06 \\
Hostelería y Turismo & 33 & 13.92 \\
Salud y Belleza & 22 & 9.28 \\
Informática y Electrónica & 44 & 18.57 \\
Textil, Calzado y Complementos & 31 & 13.08 \\
Otros & 11 & 4.64 \\
TOTALES & $\mathbf{2 3 7}$ & $\mathbf{1 0 0}$
\end{tabular}

El reparto de encuestados por sectores se presenta en la Tabla 4, con un error de muestreo global de $4,21 \%$ para un nivel de confianza del $95,5 \%$ (dos sigmas), y $p=q=1 / 2$, y se realizó mediante afijación no proporcional.

\subsection{Resultados y análisis}

Tras la recogida y depuración de la información procedente de los cuestionarios, se realizó el AFC utilizando el programa estadístico R, versión 2.9.1, (R Development Core Team, 2009), y el algoritmo implementado en el paquete "ca" (Greenacre y Nenadic, 2009), ya que proporciona algunas herramientas de análisis e interpretación no disponibles en otros procedimientos. Tras su ejecución, los primeros resultados obtenidos se muestran en el Cuadro 1.

Cuadro 1. Inercias principales de las 15 posibles dimensiones 


\begin{tabular}{|c|c|c|c|c|}
\hline $\operatorname{Dim}(\mathbf{k})$ & Valor & $\%$ & $\%$ Acum & Gráfico de Inercias \\
\hline 1 & 0.105735 & 43.3 & 43.3 & ****************************1 \\
\hline 2 & 0.046294 & 18.9 & 62.2 & $* * * * * * * * * * *$ \\
\hline 3 & 0.035849 & 14.7 & 76.9 & $* * * * * * * *$ \\
\hline 4 & 0.024136 & 9.9 & 86.7 & $* * * * * *$ \\
\hline 5 & 0.008380 & 3.4 & 90.2 & $* *$ \\
\hline 6 & 0.006874 & 2.8 & 93.0 & $* *$ \\
\hline 7 & 0.006656 & 2.7 & 95.7 & $* *$ \\
\hline 8 & 0.004155 & 1.7 & 97.4 & $*$ \\
\hline 9 & 0.002840 & 1.2 & 98.6 & $*$ \\
\hline 10 & 0.001686 & 0.7 & 99.3 & \\
\hline 11 & 0.000814 & 0.3 & 99.6 & \\
\hline 12 & 0.000441 & 0.2 & 99.8 & \\
\hline 13 & 0.000322 & 0.1 & 99.9 & \\
\hline 14 & 0.000174 & 0.1 & 100.0 & \\
\hline 15 & $8.1 \mathrm{e}-050$ & 0.0 & 100.0 & \\
\hline Total & 0.244434 & 100.0 & & \\
\hline
\end{tabular}

Como se puede observar, con las dos primeras dimensiones (Dim 1 y Dim 2) sólo se obtiene un $62.2 \%$ de inercia explicada. Por ello, es conveniente extraer una tercera dimensión (Dim 3), y así llegar al 76.9\% de explicación, porcentaje que es suficiente para poder representar de forma simplificada la estructura de percepciones asociadas a los efectos que, según los expertos encuestados, producen las técnicas de comunicación emergentes. La primera dimensión aporta un $43.3 \%$ a la explicación de la inercia, la segunda dimensión aporta un $18.9 \%$, y la tercera y última un $14,7 \%$.

La interpretación de las tres dimensiones $(\mathrm{k}=1-3)$ extraídas en función de la inercia explicada, se debe realizar a partir de las correlaciones de cada ítem con las dimensiones (COR) y de las contribuciones a la inercia de cada elemento fila y columna (CTR). Las Tablas 4 y 5 muestran todas estas magnitudes, que suponen una ayuda fundamental para entender cómo se estructuran las percepciones de los directivos encuestados.

Analizando la Tabla 5, aparecen las coordenadas para la dimensión $1(\mathrm{k}=1)$, la dimensión $2(\mathrm{k}=2)$ y la dimensión $3(\mathrm{k}=3)$. En la dimensión 1 destacan las contribuciones a la inercia (CTR) con coeficiente positivo, correspondientes a "Ofrece una imagen positiva de la marca" (IMAGEN), "Se asocia a un precio o calidad altos" (CALIDAD), "Sirve para modificar percepciones" (PERCEPCIO) y "Puede cambiar la actitud hacia un producto" (ACTITUD). Con coeficientes negativos, aparecerían conceptos como "La comunicación se propaga rápidamente" (PROPAGA), "Poca permanencia del mensaje" (NOPERMAN) y "Puede molestar al receptor" (MOLESTA).

El Gráfico $1^{5}$ muestra la polarización de estos atributos a lo largo del eje 1, lo

${ }^{5} \mathrm{Al}$ ser tres las dimensiones necesarias para representar las percepciones de los directivos, 
que supone una ayuda visual importante a la interpretación de dicha dimensión. Así, por un lado se encuentran las técnicas cuyos efectos esperados inciden en características perceptuales (posicionamiento, calidad percibida, imagen, cambio de actitudes) y, por tanto, con un carácter más estratégico. Estas técnicas son la "Comunicación 360" (COM360), la "Comunicación experiencial" (EXPER), la "Comunicación sensorial" (SENSOR) y el "Tryvertysing" (TRYVER), siendo estas tres últimas las que pueden incidir más directamente en el cambio de actitudes del receptor del mensaje.

Tabla 5. Estadísticos de las Filas (Efectos asociados a las Técnicas de Comunicación)

\begin{tabular}{|c|c|c|c|c|c|c|c|c|c|}
\hline & $\mathrm{K}=\mathbf{1}$ & COR & CTR & $K=2$ & COR & CTR & $K=3$ & COR & CTR \\
\hline Provoca sorpresa & -57 & 66 & 2 & 142 & 413 & 27 & -102 & 212 & 18 \\
\hline Técnica muy efectiva & 40 & 106 & 1 & -58 & 223 & 5 & 23 & 34 & 1 \\
\hline $\begin{array}{l}\text { Facilidad en la medición de resul- } \\
\text { tados }\end{array}$ & -210 & 96 & 10 & -380 & 318 & 77 & 104 & 24 & 7 \\
\hline $\begin{array}{l}\text { La comunicación se propaga } \\
\text { rápidamente }\end{array}$ & -452 & 562 & 117 & -154 & 65 & 31 & 240 & 158 & 97 \\
\hline No es rentable & 221 & 269 & 21 & 12 & 1 & 0 & -16 & 1 & 0 \\
\hline Mucha notoriedad & 152 & 78 & 9 & 421 & 600 & 159 & 258 & 225 & 77 \\
\hline Muy persuasiva & -39 & 8 & 1 & -39 & 8 & 1 & 326 & 571 & 118 \\
\hline Poco creíble & 83 & 66 & 4 & -200 & 384 & 51 & -103 & 101 & 18 \\
\hline Difícil de comprender & -61 & 13 & 1 & -130 & 57 & 9 & -332 & 375 & 77 \\
\hline Poca permanencia del mensaje & -598 & 831 & 225 & -151 & 53 & 33 & 127 & 37 & 30 \\
\hline $\begin{array}{l}\text { Ofrece una imagen positiva de la } \\
\text { marca }\end{array}$ & 371 & 853 & 52 & 106 & 70 & 10 & 74 & 34 & 6 \\
\hline $\begin{array}{l}\text { Puede generar otras noticias en los } \\
\text { medios }\end{array}$ & -3 & 0 & 0 & 264 & 643 & 101 & -90 & 75 & 15 \\
\hline Es útil para posicionar el producto & 457 & 500 & 64 & -27 & 2 & 1 & 401 & 384 & 145 \\
\hline Se asocia a un precio o calidad altos & 548 & 650 & 101 & 126 & 34 & 12 & 144 & 45 & 21 \\
\hline Sirve para modificar percepciones & 391 & 890 & 85 & 16 & 1 & 0 & 15 & 1 & 0 \\
\hline $\begin{array}{l}\text { Sirve para modificar comporta- } \\
\text { mientos }\end{array}$ & 245 & 194 & 23 & -307 & 306 & 81 & -191 & 118 & 40 \\
\hline $\begin{array}{l}\text { Puede cambiar la actitud hacia un } \\
\text { producto }\end{array}$ & 383 & 753 & 72 & -114 & 67 & 15 & -30 & 4 & 1 \\
\hline $\begin{array}{l}\text { Puede no ser entendida por el } \\
\text { receptor }\end{array}$ & -247 & 171 & 27 & 399 & 446 & 164 & -332 & 309 & 146 \\
\hline Puede molestar al receptor & -508 & 733 & 137 & 52 & 8 & 3 & 49 & 7 & 4 \\
\hline Puede confundir al receptor & -288 & 422 & 36 & 207 & 219 & 43 & -217 & 240 & 61 \\
\hline Potencia la relación con el receptor & 188 & 89 & 13 & -461 & 540 & 177 & -330 & 277 & 117 \\
\hline
\end{tabular}

En el extremo opuesto del eje 1, aparecen las técnicas con efectos de carácter más

se ha optado por realizar tres gráficos bidimiensionales. No obstante, el Gráfico 4 muestra la estructura tridimensional del análisis. 
táctico, con posible incidencia negativa en cuanto a la receptividad del destinatario del mensaje (no permanente, propagación rápida, puede molestar). Entre estas técnicas se sitúan la "Comunicación móvil" (MOVIL), el "Microblogging" (MICRO), el "Marketing de Proximidad" (PROXIM), el "Buzz marketing" (BUZZ) y la "Comunicación viral" (COMVIR).

La dimensión 2, muestra una polarización clara entre las técnicas de comunicación cuyos efectos se asocian a "Potencia la relación con el receptor" (RELACION), "Facilidad en la medición de resultados" (MEDICION) y "Sirve para modificar comportamientos" (COMPORTA), frente a las técnicas de comunicación que producen efectos directamente relacionados con la notoriedad y la generación de noticias en los medios (NOTORIED y GENENOTI, respectivamente). De este modo, se puede distinguir entre aquellas técnicas que se espera que potencien comportamientos y relaciones, frente a aquellas cuyos efectos se están más asociados con el "ruido" y la generación de recuerdo. Entre las técnicas que favorecen la medición se encuentra la comunicación móvil (MOVIL), y la que más favorece las relaciones y la modificación de comportamientos es la comunicación en redes sociales (REDES).

Respecto a la notoriedad, el "Ambient Marketing" (AMBIEN) y el "Street Marketing" (STREET), son las que aparecen con una fuerza de asociación mayor.

Tabla 6. Estadísticos de las Columnas (Técnicas de Comunicación)

$\begin{array}{lrrrrrrrrr} & \text { K=1 } & \text { COR } & \text { CTR } & \text { K=2 } & \text { COR } & \text { CTR } & \text { K=3 } & \text { COR } & \text { CTR } \\ \text { Comunicación 360 } & 546 & 619 & 273 & -11 & 0 & 0 & -309 & 198 & 218 \\ \text { Comunicación viral } & -362 & 253 & 76 & -535 & 554 & 267 & 143 & 40 & 30 \\ \text { Buzz marketing } & -371 & 352 & 73 & -430 & 471 & 158 & 64 & 10 & 5 \\ \text { Comunicación móvil } & -433 & 293 & 107 & 299 & 140 & 82 & -507 & 401 & 365 \\ \text { Advertainment } & -114 & 92 & 9 & 203 & 291 & 46 & -16 & 2 & 0 \\ \text { Engagement marketing } & -120 & 146 & 10 & 163 & 270 & 31 & -34 & 12 & 2 \\ \text { Advergaming } & -161 & 118 & 16 & 277 & 351 & 77 & 161 & 118 & 41 \\ \text { Street marketing } & 274 & 329 & 63 & -266 & 310 & 95 & -43 & 8 & 4 \\ \text { Ambient marketing } & 190 & 249 & 26 & -246 & 417 & 70 & -37 & 10 & 2 \\ \text { Comunicación experien- } & 236 & 425 & 50 & 66 & 33 & 6 & 125 & 120 & 35 \\ \text { cial } & & & & & & & & & \\ \text { Comunicación sensorial } & 269 & 377 & 60 & 118 & 72 & 18 & 225 & 264 & 105 \\ \text { Tryvertising } & 153 & 158 & 18 & 194 & 253 & 46 & 262 & 463 & 131 \\ \text { Micro-blogging } & -488 & 733 & 132 & 50 & 8 & 2 & 41 & 5 & 2 \\ \begin{array}{l}\text { Comunicación en Redes } \\ \text { Sociales }\end{array} & -367 & 623 & 85 & 71 & 23 & 5 & -8 & 0 & 0 \\ \text { Marketing radical } & 12 & 1 & 0 & 207 & 268 & 38 & 76 & 36 & 8 \\ \text { Marketing de proximidad } & -2 & 0 & 0 & -248 & 266 & 58 & -186 & 150 & 51\end{array}$


Gráfico 1. Representación gráfica de las dimensiones 1 y $2(\mathrm{~K}=1 \text { y K=2 })^{6}$

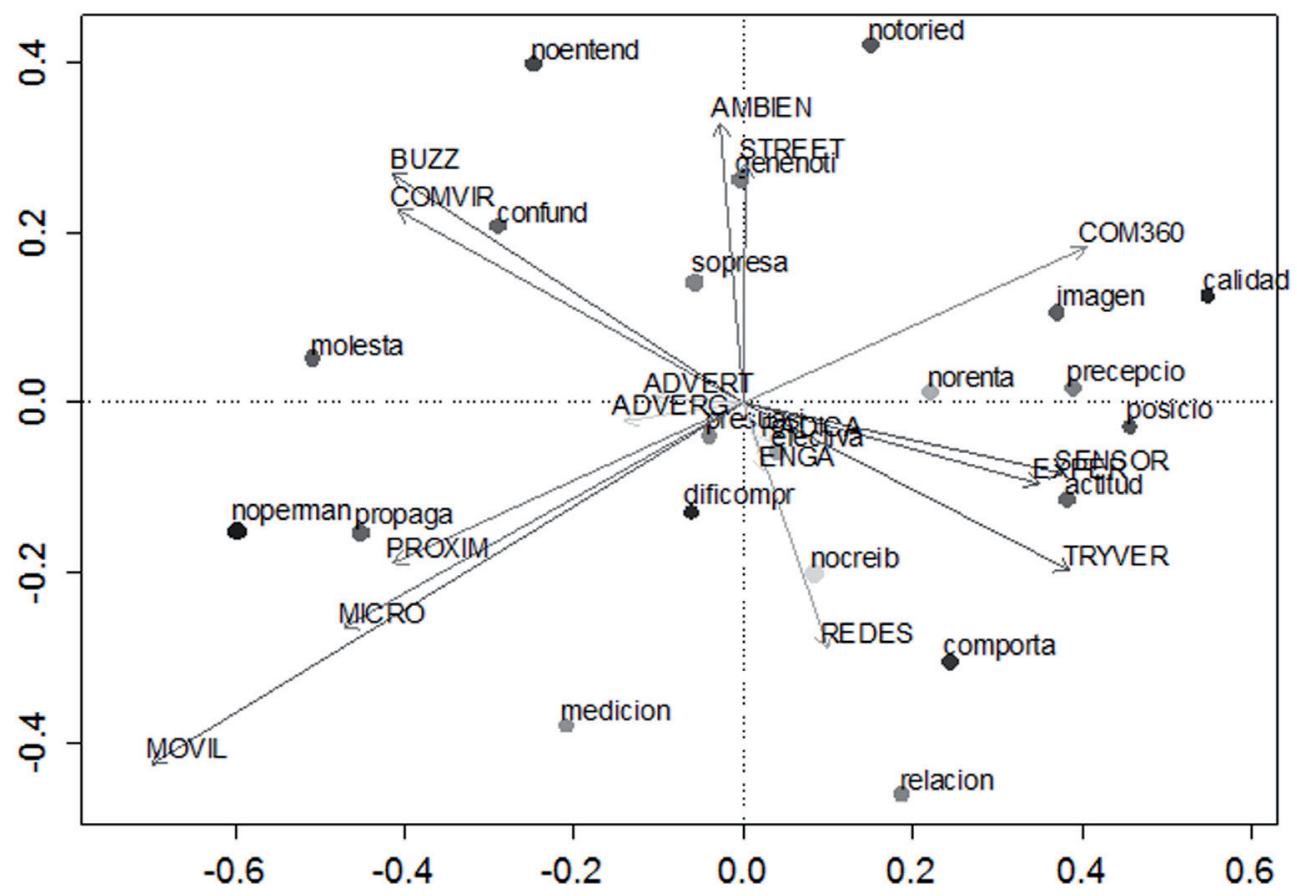

En cuanto a la dimensión 3, representada tanto en el Gráfico 2 (frente a la dimensión 1) como en el Gráfico 3 (frente a la dimensión 2), la características que más destacan con respecto al resto son, con coeficientes positivos "Es útil para posicionar el producto" (POSICIO), "Muy persuasiva" (PERSUASI). En el polo opuesto de este tercer eje, con coeficientes negativos, aparecen los efectos asociados con "Potencia la relación con el receptor" (RELACION), "Puede no ser entendida por el receptor" (NOENTEND) y "Difícil de comprender" (DIFICOMPR). Entre las técnicas que potencian los efectos persuasivos y el posicionamiento, en este tercer eje, aparece la "Comunicación 360" (COM360), mientras que el "Advergaming" (ADVERG) y el "Advertainment" (ADVERT) pueden producir efectos de confusión, y el "Engagement Marketing" (ENGA) efectos que potencian las relaciones e influyen en el comportamiento (ver Gráficos 2 y 3). Finalmente, el Gráfico 4 muestra las tres dimensiones de forma conjunta.

${ }^{6}$ El tamaño de los puntos es proporcional a su "masa" (mayor tamaño, mayor "masa") y la intensidad del color muestra la magnitud de la "contribución relativa" a la inercia (más oscuro cuanto mayor es la contribución). 
Gráfico 2. Representación gráfica de las dimensiones 1 y $3(\mathrm{~K}=1$ y K=3)

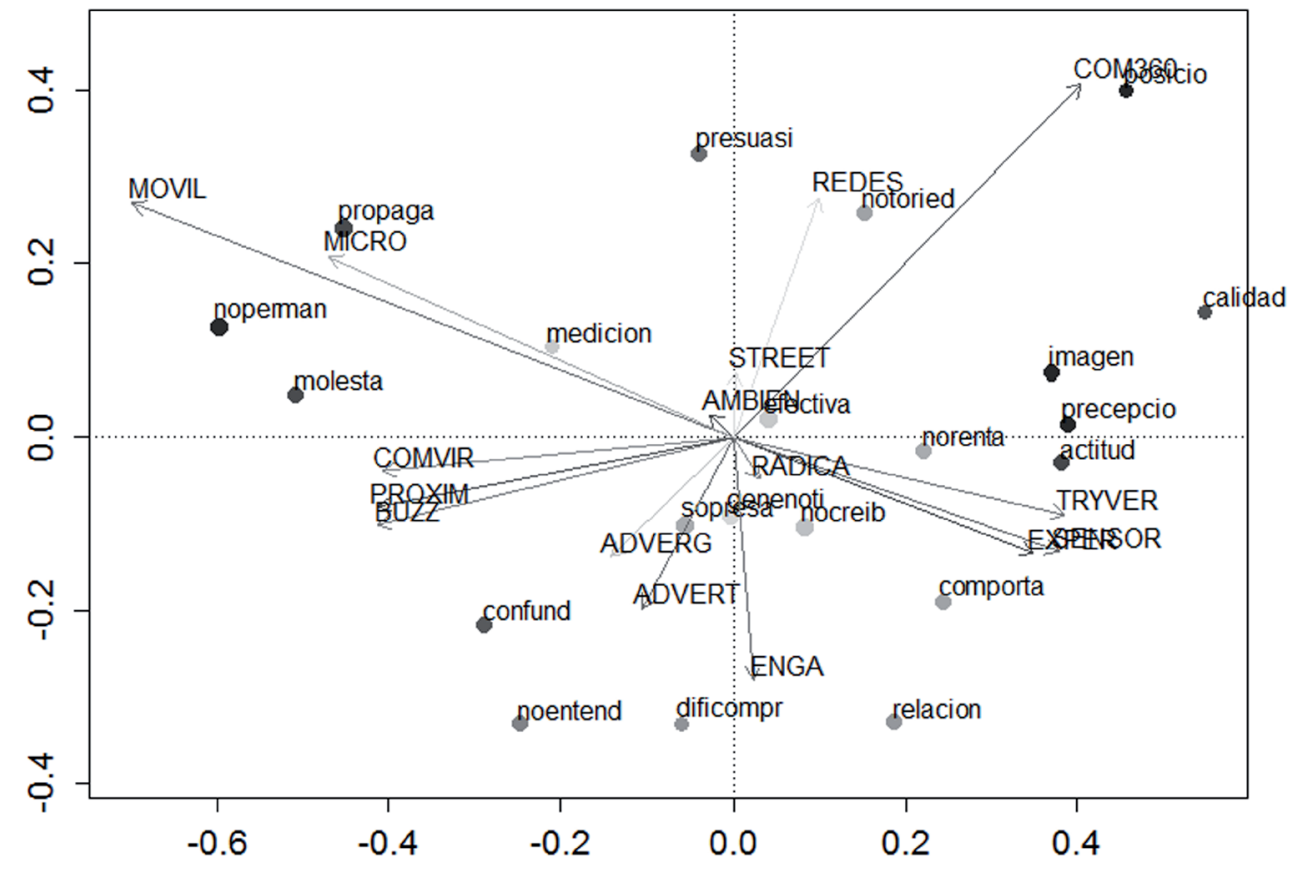

\section{Conclusiones}

Las principales conclusiones de este trabajo se centran en las diferencias entre los efectos que, según la amplia muestra de expertos utilizada, pueden atribuirse al conjunto de técnicas emergentes en comunicación comercial.

Según los análisis efectuados, se pone de manifiesto que existen tres ejes claros de clasificación. En primer lugar, aparece un primer criterio de diferenciación, basado en la orientación estratégica o táctica en la comunicación. En segundo lugar, también se evidencia una diferenciación evidente entre técnicas con una orientación puramente dirigidas al recuerdo o notoriedad, frente a aquellas cuyos efectos atribuidos tienen más relación con la potenciación de relaciones y la modificación de comportamientos. 
Gráfico 3. Representación gráfica de las dimensiones 2 y $3(\mathrm{~K}=2$ y $\mathrm{K}=3)$

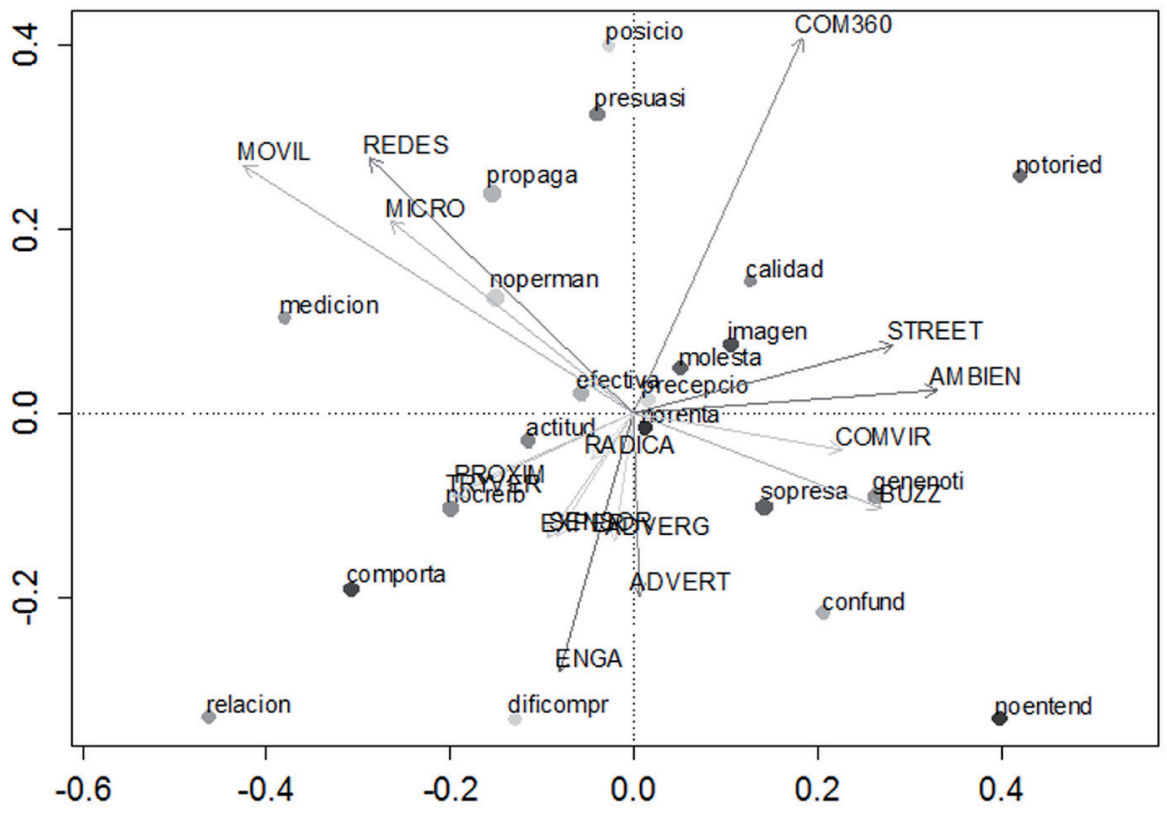

Gráfico 4. Representación gráfica de las dimensiones 1,2 y $3(\mathrm{~K}=1, \mathrm{~K}=2$ y $\mathrm{K}=3)$

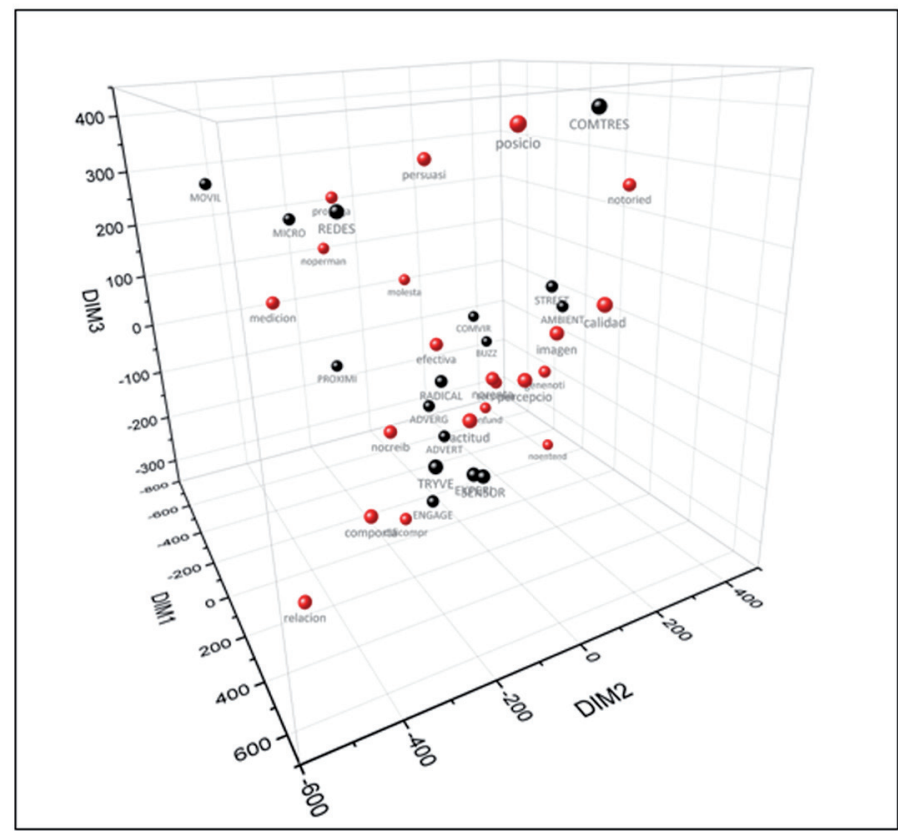


En tercer lugar, aparece una diferenciación interesante entre las técnicas más orientadas a producir efectos relacionados con la persuasión, frente a otras que pueden producir confusión en el receptor y que, en principio, deberían ser evitadas. De forma más específica, las técnicas analizadas quedarían clasificadas del siguiente modo:

- Orientación estratégica: Comunicación 360, Comunicación Experiencial, Comunicación Sensorial y Tryvertising.

- Orientación Táctica: Comunicación móvil, el Microblogging, el Marketing de Proximidad, el Buzz marketing y la Comunicación viral.

- Orientación hacia el recuerdo o notoriedad: Ambient Marketing y el Street Marketing.

- Potenciación de relaciones y modificación de comportamientos: Comunicación en redes sociales y Engagement Marketing.

- Orientación a efectos relacionados con la persuasión: Comunicación 360.

- Técnicas que pueden producir confusión: Advergaming y Advertainment.

Las limitaciones de esta investigación se refieren básicamente al carácter agregado de los datos. Es posible que aparezcan diferencias perceptuales significativas por sectores de actividad, o incluso por antigüedad del mercado. Sería interesante averiguar si esas diferencias realmente existen, para poder definir un mapa conceptual aproximado, y así orientar la elección de una técnica de comunicación particular. Otra de las posibles limitaciones viene dada por la propia naturaleza descriptiva del estudio, que revela qué es lo que perciben los directivos sobre los efectos que estas técnicas pueden producir en el destinatario del mensaje, pero no explica cuál puede ser el origen de estas percepciones. Por último, al ser un trabajo estático, realizado en un momento del tiempo concreto, es posible que estos efectos percibidos puedan ir variando, especialmente por la novedad asociada a la mayoría de estas técnicas de comunicación.

Las líneas futuras de investigación pueden sintetizarse en dos grupos. En primer lugar, sería interesante estudiar los efectos reales en los destinatarios de la comunicación, los consumidores actuales o potenciales, y contrastar los resultados con los que se han obtenido de los directivos encuestados. En segundo lugar, y complementario con el primero, se abre un campo de investigación clave, en el que se debería intentar evaluar la eficacia de estas técnicas de comunicación en términos de efectos producidos en la audiencia y objetivos conseguidos. Estas dos áreas de estudio pueden ayudar a clarificar un panorama complejo, y a veces confuso, en el que se debe realizar un esfuerzo por comprender y sistematizar el uso de las nuevas técnicas de comunicación.

\section{Referencias bibliográficas}

AHUJA, R.D.; MICHELS, T.A.; WALKER, M.M. y WEISSBUCH, M. (2007): «Teen perceptions of disclosure in buzz marketing» The Journal of Consumer Marketing, 24 (3), 151-159.

ASQUITH, K., y HEARN, A. (2012): «Promotional Prime Time:” Advertainment," Internal Network Promotion, and the Future of Canadian Television» Canadian Journal of Communication, 37(2): 
BAMBA, F. y BARNES, S.J. (2007): «SMS Advertising, Permission and the Consumer: a Study» Business Process Management Journal, 13 (6), 815-829.

BELIĆ, S., y JÖNWSSON, E. (2012): Guerrilla marketing: and its effects on consumer behavior (Doctoral dissertation, Kristianstad University):

BENZECRI, J.P. (1973): «La Taxinomie, Vol. I. L'Analyse des Correspondances» Paris.

BENZECRI, J.P. (1973): «L'Analyse des Donnees, vol. 2. L'Analyse des Correspondances» Paris.

BOSMANS, A. (2006): «Scents and Sensibility: When Do (In)Congruent Ambient Scents Influence Product Evaluations?» Journal of Marketing, 70 (3), 32-43.

CAMBRA, J., MELERO, I., y SESE, F. J. (2012): «Aproximación al concepto de "engagement": un estudio exploratorio en el sector de la telefonía móvil». Universia Business Review, (33), 84-103.

CARL, W.J. (2006): «What's all the buzz about? Everyday Communication and the Relational Basis of Word-of-Mouth and Buzz Marketing Practices». Management Communication Quarterly: McQ., 19 (4), 601-635.

CHRISTIANSEN, T. y TAX, S. S. (2000): «Measuring word of mouth: the questions of who and when?» Journal of Marketing Communications, 6 (3), 185-199.

CHU, S. C. (2011): «Viral advertising in social media: participation in Facebook Groups and Responses among college-Aged users» Journal of Interactive Advertising, 12(1), 30-43.

CHUNG, C. y DARKE, P. (2006): «The consumer as advocate: Self-relevance, culture, and word-of-mouth» Marketing Letters, 17 (4), 269-279.

COLE, M. (2007): «The networked consumer: a critical review and assessment» Journal of Customer Behaviour, 6 (1): 5-18.

DAVIES, B.J.; KOOIJMAN, D. y Ward, P. (2003): «The Sweet Smell of Success: O1faction in Retailing» Journal of Marketing Management, 19 (5-6), 611-627.

FERRIS, M. (2007): «Insights on Mobile Advertising, Promotion, and Research» Journal of Advertising Research, 47 (1), 28-37.

GAO, T. T., SULTAN, F., y ROHM, A. J. (2010): «Factors influencing Chinese youth consumers' acceptance of mobile marketing» Journal of Consumer Marketing,27(7), 574-583.

GLASER, B.G. y STRAUSS, A. L. (1967): The discovery of grounded theory: Strategies for qualitative research. Chicago: Aldine Publishing Company.

GREENACRE, M. y NENADIC, O. (2009): «ca: Simple, Multiple and Joint Correspondence Analysis. R package version 0.3-2» Disponible en: http://www.carme-n. org/.

HAINES, E. (2009): «The dos and don'ts of proximity marketing in sponsorship» Journal of Sponsorship, 2 (2), 113-119.

HANSEN, L. K., ARVIDSSON, A., NIELSEN, F. Å., COLLEONI, E., y ETTER, M. (2011): «Good friends, bad news-affect and virality in twitter» Future Information Technology, 34-43.

HAVLENA, W.; CARDARELLI, R. y DE MONTIGNY, M. (2007): «Quantifying the Isolated and Synergistic Effects of Exposure Frequency for TV, Print, and Internet 
Advertising» Journal of Advertising Research, 47 (3), 215-221.

HUDSON, S. y HUDSON, D. (2006): «Branded Entertainment: A New Advertising Technique or Product Placement in Disguise? » Journal of Marketing Management, 22 (5-6), 489-504.

HULTÉN, B. (2012): «Sensory cues and shoppers' touching behaviour: the case of IKEA» International Journal of Retail \& Distribution Management, 40(4), 273289.

HUNG, K.H. y YIYAN Li, S.(2007): «The Influence of eWOM on Virtual Consumer Communities: Social Capital, Consumer Learning, and Behavioral Outcomes» Journal of Advertising Research, 47 (4), 485-495.

JACKSON, K. (2009): «Influencing behaviour towards a brand through experiential marketing and sponsorship» Journal of Sponsorship, 2 (2), 164-169.

JURCA, A. M. (2012): What is and why do we need ambient advertising? A theoretical approach. Marketing From Information to Decision, (5), 210-221.

KRAUS, S., HARMS, R., y FINK, M. (2010): «Entrepreneurial marketing: moving beyond marketing in new ventures». International Journal of Entrepreneurship and Innovation Management, 11(1), 19-34.

LEE, M. y YOUN, S. (2009): «Electronic word of mouth (eWOM)» International Journal of Advertising, 28 (3), 473-499.

LEE, T. H., y CHANG, Y. S. (2012): «The influence of experiential marketing and activity involvement on the loyalty intentions of wine tourists in Taiwan» Leisure Studies, 31(1), 103-121.

LEEK, S. y CHRISTODOULIDES, G. (2009): «Next-Generation Mobile Marketing: How Young Consumers React to Bluetooth-Enabled Advertising. Journal of Advertising Research, 49 (1), 44-53.

MCARTHUR, D. N. y GRIFFIN, T. A. (1997): «Marketing Management View of Integrated Marketing Communications. Journal of Advertising Research, 37 (5), 19-26.

MILLER, R., y LAMMAS, N. (2010): «Social media and its implications for viral marketing» Asia Pacific Public Relations Journal, 11(1), 1-9.

MORIN, S. y DUBÉ, L.; CHEBAT, J.C. (2007): «The role of pleasant music in servicescapes: A test of the dual model of environmental perception» Journal of Retailing, 83 (1), 115-130.

MORRIN, M. y RATNESHWAR, S. (2003): «Does It Make Sense to Use Scents to Enhance Brand Memory?» Journal of Marketing Research (JMR), 40 (1), 10-26.

MORT, G.S. y DRENNAN, J. (2007): «Mobile Communications: A Study of Factors Influencing Consumer Use of m-Services» Journal of Advertising Research, 47 (3), 302-312.

NAMMIR, D. S. S., MARANE, B. M., y ALI, A. M. (2012): «Determine the Role of Customer Engagement on Relationship Quality and Relationship Performance»European Journal of Business and Management, 4(11), 27-36.

NELSON, M.R.; KEUM, H. y YAROS, R.A. (2004): «Advertainment or Adcreep? Game Players' Attitudes toward Advertising and Product Placements in Computer Games» Journal of Interactive Advertising, 4 (3):

OKAZAKI, S. (2009): «Social Influence Model and Electronic Word of Mouth» Inter- 
national Journal of Advertising, 28 (3), 439-472.

PETKUS Jr., Ed. (2004): «Enhancing the application of experiential marketing in the arts» International Journal of Nonprofit \& Voluntary Sector Marketing, 9 (1), 49-56.

R DEVELOPMENT CORE TEAM (2009): R: A language and environment for statistical computing. R Foundation for Statistical Computing, Vienna, Austria. ISBN 3-900051-07-0. Disponible en: http://www.R-project.org.

ROMANOV, A. (2012): «Proximity Marketing Transforms the Customer Experience» Customer Intertion Solutions 31.1 (2012): 20-21.

SANCHEZ, J. y PINTADO, T. (2010): «Análisis perceptual de las técnicas emergentes en comunicación. Un estudio empírico con implicaciones estratégicas» Adresearch. Revista internacional de investigación en Comunicación. ESIC.

SASHI, C. M. (2012): «Customer engagement, buyer-seller relationships, and social media» Management Decision, 50(2), 253-272.

SCHMITT, B. (1999): «Experiential Marketing» Journal of Marketing Management, $15(1-3), 53-67$.

SHANKAR, V., VENKATESH, A., HOFACKER, C., y NAIK, P. (2010): «Mobile marketing in the retailing environment: current insights and future research avenues» Journal of Interactive Marketing, 24, 111-120.

SHUKLA, T. (2010): «Factors affecting 'Internet marketing'campaigns with reference to viral and permission marketing» The IUP Journal of Management Research, 9(1), 26-37.

SMITH, T.; COYLE, J.R.; LIGHTFOOT, E. y SCOTT, A. (2007): «Reconsidering Models of Influence: The Relationship between Consumer Social Networks and Wordof-Mouth Effectiveness. Journal of Advertising Research, 47 (4), 387-397.

STRAUSS, A. y CORBIN, J. (1998): «Basics of qualitative research: Techniques and procedures for developing grounded theory (2nd ed.): Thousand Oaks: Sage.

TEICH, A. (2008): «Using Company Blogs to Win over Decision Makers» Publishing Research Quarterly, 24 (4), 261-266.

THOMAS G. M. (2004): «Building the buzz in the hive mind» Journal of Consumer Behaviour, 4 (1), 64-72.

TRUSOV, M.; BUCKLIN, R.E. y PAUWELS, K. (2009): «Effects of Word-of-Mouth Versus Traditional Marketing: Findings from an Internet Social Networking Site» Journal of Marketing, 73 (5), 90-102.

TURK, T.; NEWTON, F.J. y EWING, M.T. (2006): «Using ambient media to promote HIV/AIDS protective behaviour change» International Journal of Advertising, 25 (3), 333-359.

VAN NOORT, G., ANTHEUNIS, M. L., y VAN REIJMERSDAL, E. A. (2012): «Social connections and the persuasiveness of viral campaigns in social network sites: Persuasive intent as the underlying mechanism» Journal of Marketing Communications, 18(1), 39-53.

VARNALI, K., y TOKER, A. (2010): «Mobile marketing research: The-state-of-theart» International Journal of Information Management, 30(2), 144-151.

VILLA, P. (2012): Estudio Infoadex de la Inversión Publicitaria en España 2012. Infoadex, S.A. Disponible en: http://www.infoadex.es/Resumen_Estudio_Inversio- 
nes_InfoAdex 2012.pdf

WAIS, J.S. Y CLEMONS, E.K. (2008): «Understanding and Implementing Mobile Social Advertising» International Journal of Mobile Marketing, 3 (1), 12-18.

WANG, A. (2006): «Advertising Engagement: A Driver of Message Involvement on Message Effects» Journal of Advertising Research, 46 (4), 335-368.

WANG, A. (2007): «Branding over Mobile and Internet Advertising: the Cross-Media effect» International Journal of Mobile Marketing, 2 (1), 34-42.

WETZER, I. M.; ZEELENBERG, M. y PIETERS, R. (2007): «Never eat in that restaurant, I did!: Exploring why people engage in negative word-of-mouth communication» Psychology \& Marketing, 24 (8), 661-680.

WHELAN, S. y WOHLFEIL, M. (2006): «Communicating brands through engagement with 'lived' experiences» Journal of Brand Management, 13 (4-5), 313-329.

WOO JUN, J. y LEE, S. (2007): «Mobile Media Use and its Impact on Consumer Attitudes toward Mobile Advertising» International Journal of Mobile Marketing, 2 (1), 50-58. 